\title{
De como "O grito" de Luís Miguel Nava discute o valor da escrita
}

\author{
Alilderson de Jesus \\ (Universidade Federal do Rio de Janeiro)
}

\section{RESUMO}

Pretendo analisar, a partir de "O grito", poema de Luís Miguel Nava, como a escrita literária, tão barateada pelo mercado, pode discutir seu próprio lugar no mundo. Serão colocadas em evidência as maneiras com que o autor propõe o absurdo e o inesperado na escrita poética, quando mistura elementos aparentemente díspares como o ambiente de terror e a metalinguagem.

PALAVRAS-CHAVE: Mercado, Escrita, Luís Miguel Nava.

\begin{abstract}
I intend to analyze, from "O grito", Luis Miguel Nava's poem, as the literary writing, so cheapened, can argue its proper place in the world. The ways how that the author considers the nonsense and the unexpected one in the poetical writing will be placed in evidence, cause the text mixture elements apparently stranges as the environment of terror and the metalanguage.
\end{abstract}

KEYWORDS: Market, Writing, Luís Miguel Nava. 
Quem escreve e quem lê estão perdidos numa selva de papéis podres chamada literatura. Isso inibe o nascimento e a produção do escritor, do poeta e do leitor que aspiram, de fato, à ficção-ensaio-poesia-pensamento.

Um dos motivos desse fenômeno é o fato de abrirmos mão do pensamento como guia. "Pensamento", aliás, é uma palavra que beira o desuso. Isso porque, dia e noite, somos acordados para um mundo de facilidades tecnológicas capazes de nos desobrigar de usar o pensamento, seja como palavra, seja como ação reflexiva. Já a literatura, um dos tantos meios de produzir reflexão, apesar ser uma dissonância numa sinfonia de notas frias, parece um grito lançado à surdez em meio ao barulho das moedas do mercado.

Aliás, a sensação que às vezes tenho é de que "barulho" é a única produção de nosso tempo. Explosões, êxtases, grunhidos, falsas pequenas mortes, verdadeiros genocídios. Tudo isso para erguer e cuidar do que chamamos civilização. Uma civilização barulhenta que silencia apenas para não se manifestar sobre as atrocidades que promove.

Por outro lado, uma das possíveis manifestações que pode abrir fileiras contra tudo isso, a literatura está, no entanto, cada vez mais próxima de ser, ela, silenciada. Apesar de ser, para muitos (mesmo que estes sequer tomem ciência disto) "uma coisa sem a qual ou com a qual tudo fica tal e qual", a literatura resiste aos barulhos destrutivos sendo ela, a literatura, um grito.

Capaz de alavancar sentimentos e sensações humanas, a literatura - que ironicamente precisa da civilização e dos meios de produção desta mesma civilização para existir - é sua potencial inimiga. Isso porque nossa sociedade que frequenta cafés literários e shopping centers comporta-se como costumam fazer os suicidas diante da mais remota possibilidade de seu resgate.

Diante disso, à sociedade que corre contra o tempo de seu relógio e não contra o tempo de seu tempo, restam os happy ends dos tristes fins de semana. Para ela, o mercado sabe vender a ilusão de que sua frequência nos cafés literários e shoppings a torna dona e não presa deste cosmos de possibilidades. Isso deixa a sociedade feliz com a "felicidade" que interessa ao mercado, enquanto que, à literatura, à escrita em seu sentido mais artístico, interessa "não deixar" "felizes". Talvez, para a literatura, melhor seria varrê-los (cafés literários, shoppings e quejandos) do mapa, provocando uma crise na idéia vaga que se tem de felicidade.

No entanto, o agente provocador (o escritor, o poeta) dessa crise, e o desejante dos efeitos dessa provocação (o leitor), são párias na "selva de papéis podres"; praticam sua paixão como se fosse ela um cigarrinho clandestino num banheiro da escola, um pequeno delito sem grandes consequências. É possível que seja isso decorrente do fato de o leitor, de modo geral, não ter dinheiro para resgatar "os papéis podres" da máquina trituradora a que se costuma chamar mercado editorial e, por sua vez, do fato de o escritor ser movido por ambições literárias e não financeiras, o que, paradoxalmente ou não, é um dos motivos do encarecimento do preço do livro.

Ocorre que, às vezes, estamos pouco atentos ao fato de que, embora o livro possa conter literatura, livro e literatura não são a mesma coisa. O livro pode transportar ou transbordar literatura. Mas o livro é um livro: um objeto perecível feito de papel; e papel, como se sabe, aceita qualquer tinta. Seja a tinta do sensacionalismo (presente nas biografias de celebridades), que torna público o que deveria pertencer à esfera do privado, seja a tinta das fórmulas mágicas capazes de resolver males privados, como se a solução destes males viesse de um procedimento único, receitável por livros de autoajuda. 
Diante disso, não é difícil concluir que o mercado, seja ele qual for, não faz as diferenciações que não lhe interessam. Seus princípios são os que equiparam um quadro de Edvard Munch a uma biografia dum astro pop, e um modelo caro de automóvel às expectativas do lucro.

Por outra via, as expectativas que movem um escritor como Franz Kafka, por exemplo, são bem outras, como podemos ver no trecho de uma carta desse escritor a seu amigo Oskar Pollak:

No fim das contas, penso que devemos ler somente livros que nos mordam e piquem. Se o livro que estamos lendo não nos sacode e acorda como um golpe no crânio, por que nos darmos ao trabalho de lê-lo? Para que nos faça feliz, como diz você? Meu Deus, seríamos felizes da mesma forma se não tivéssemos livros. Livros que nos façam felizes, em caso de necessidade, poderíamos escrevê-los nós mesmos. Precisamos é de livros que nos atinjam como o pior dos infortúnios, como a morte de alguém que amamos mais do que a nós mesmos, que nos façam sentir como se tivéssemos sido banidos para a floresta, longe de qualquer presença humana, como um suicídio. Um livro tem de ser um machado para o mar gelado de dentro de nós. É nisso que acredito. (KAFKA apud MANGUEL, 1998, p. 113)

Ocorre que a crença de Kafka em livros que mordam e piquem esbarra nos anseios outros duma sociedade induzida pela ideia de felicidade permanente de que falei há pouco, seja esta felicidade advinda dum "Paraíso Prometido" pelas Sagradas Escrituras, seja ela oriunda do "paraíso do consumo". Este último, aliás, produz uma estranha contradição no imaginário dos postulantes a esse tipo de "fortuna". Uma contradição a que o poeta Luis Maffei faz referência em seu texto ensaístico "A ética (?) e a felicidade (!) dos garotos-propaganda". Segundo o poeta, "As pessoas ainda repetem por aí que a felicidade não se compra, mas agem distintamente, pois não vêem muitas hipóteses de prazer fora do ato de compra. E comprar a própria felicidade tornou-se algo natural, mais que isso, tornou-se o grande modo de obtê-la." (MAFFEI, 2009, p. 39)

Outra estranha contradição, que de algum modo ou de todo modo dialoga com a que é produzida pelo paraíso de consumo, é o fato de Kafka ser um "inferno", "um golpe no crânio" de qualquer alma sensível e, ainda assim, ser um escritor bem assimilado pela cultura de massas. Apesar de seus livros perturbadores, objetos de varias teses e análises críticas, Kafka teve e tem muito de sua produção adaptada ao teatro, ao cinema e a outras formas de entretenimento, não excluindo os quadrinhos. A mais conhecida adaptação inspirada no livro homônimo é o filme O processo, de Orson Welles.

Contudo, essa assimilação pode ser explicada pelo fato de a obra kafkiana possuir uma linguagem direta e econômica, aliada à falsa aparência dos romances de suspense $O$ suspense - assim como o apelo ao emotivo - costuma ser usado pela Indústria Cultural, todavia apenas para produzir receptividade. Isso não ocorre com Kafka, que provoca em muitos críticos e leitores uma inquietação implacável em virtude da densidade que emerge do interior dessa escritura, mas só emerge porque opta por não deslizar na superfície da linguagem como quem se diverte numa pista de patinação. 
De fato, o que se pode concluir a partir disso tudo é que estamos diante de mais um dos tantos paradoxos que alimentam a costumeira alienação. A provocação Kafka transformada em entretenimento pode resultar em grande arte, como ocorre com o filme de Welles, assim como a literatura pode ser transformada em "pequena morte" para perversões inocentes. Basta olharmos o que ocorre com Sade, outro provocador assimilado. Sua presença em nossas vidas dá-se mais por uma deturpação adjetiva (o termo "sádico") do que pela literatura que este "sádico" produz. Mas Sade pode ser visto em peças, filmes, quadrinhos e... livros! A sociedade de consumo pode comprá-lo na pior embalagem e Sade sequer pode protestar. Resta, no entanto, ao real leitor de Sade ou de qualquer outro bem literário dar um salto.

Isto porque o leitor - um suicida a não ser resgatado - quer a contradição, quer a dicção outra que não a promovida pelo barulho da abertura dos pacotes de felicidade. Ele sabe que a realidade é feita de paradoxos insolúveis e de axiomas inventados, às vezes, por nossa autoindulgência. Sabe e procura espantar-se e "co-mover-se" com tais paradoxos, não restritos, a propósito, apenas à maquinaria do mercado editorial ou aos desígnios da cultura de massa.

Com uma assustadora frequência, na medida em que abdicamos da capacidade de estranhar coisas estranhas, tropeçamos nessas muitas contradições. Começamos a nos afastar desse leitor suicida. Acostumamos-nos com "o que não deveria ser", e assim cuidamos para não tropeçar "no que deveríamos fazer" para "o que deveria ser" tornar-se presente.

É como se algures uma engrenagem que não pudéssemos travar nos tornasse vítimas de um destino inexpugnável. Uma sorte que, como um bilhete-de-frasesfeitas trazido pelo bico de um papagaio, nos conforta e nos aniquila. Isso porque, também de forma costumeira, não nos damos conta de que, se Kafka e Sade podem ser entretenimento, o destino pode ser outra coisa. Acreditamos quase sempre numa via de mão única, numa situação cujas fronteiras muito rígidas nos permitem um horizonte muito pequeno.

A escrita, por ser uma complicadora de ideias, implode o círculo vicioso e com ele grande parte de nossos vícios, principalmente os de linguagem. A poesia, que é uma forma de escrita extremamente marginalizada e assimilada por certo mercado o mais das vezes discreto, implode a linguagem, o que torna a escrita poética ainda mais refratária à felicidade.

Assim sendo, que valor tem o poeta nessa situação? Um poeta como, por exemplo, Luís Miguel Nava, assassinado em 1995 em seu apartamento em la rue de Madalene, em Bruxelas? Um poeta cuja Poesia Completa, prefaciada por Fernando Pinto Amaral e posfaciada por Gastão Cruz, não foi publicada no Brasil? Afinal, Luís Miguel Nava é um poeta, português, homossexual e um morto que não é astro pop, portanto não interessa à indústria. Não se pode ganhar dinheiro com ele. O que o torna, portanto, irrelevante para as "receitas". E põe-no à margem das "importâncias".

Para a o mercado, a biografia ou a arte de Luís Miguel Nava - muito maior e mais que as duas ou três linhas irônicas que esbocei sobre a vida deste poeta é só alguma coisa vaga que dormita no Google. Ou seja, é alguma coisa jogada numa cibernética lata de lixo entre reproduções de quadros famosos, notícias sobre o trânsito ou fotos do armador do New York Knicks.

Esta atmosfera que descrevo, não sem certa dramaticidade, vem-me justamente por causa da leitura de um poema de Nava cujo título é homônimo ao de um quadro do supracitado Edvard Munch: "O grito". 
Mas, antes de lançar-me ao poema propriamente, deixo uma provocação como pergunta: se um poeta não pode ser trocado por dinheiro - num mundo em que a existência parece ser cada vez mais refém de ser trocada por dinheiro , como e por que existe um poeta? Costuma-se dizer, inclusive, que há mais poetas que seus leitores. Afinal, poetas são publicados aqui e ali. Tanto é verdade que fui a diversos lançamentos de livros de poesia regados a elegantes coquetéis: "mundo paralelo" de interessados em comprar poesia e poetas.

Confesso que a visita a este "mundo" produz-me sempre uma sensação antitética. Ao mesmo tempo em que a publicação de livros de poesia realiza-se para mim como uma concessão do mercado (e o mercado não faz concessões), por outro lado, a mesma publicação faz-me crer numa vitória da poesia contra o mercado, já que, como sempre se diz entre poetas e afins, "a poesia é e sempre será para poucos", e poucos não consolidam o mercado. Ou consolidam?

Dito isto, subitamente parto para "O grito" - poema de Vulião - como quem parte para uma garganta cheia de espinhos, como a loucura de Herberto Helder - “(...) a loucura tem espinhos como uma garganta” (HELDER, 2006, p. 107):

Corria pela rua acima quando a súbita explosão dum grito o fez parar instantaneamente. Todo o seu corpo estremeceu. O que ele desde sempre receara acabara de ocorrer: algures, nesse momento, uma caneta começara a deslizar sobre uma folha de papel, dando assim corpo àquele grito que de há muito, como as esculturas no interior da pedra, se mantinha na expectativa desse simples gesto dum escritor para atingir a realidade. Tapou os ouvidos com as mãos. O grito mais não era que um sinal, mas o que esse sinal lhe transmitia deixava-o aterrado. Acabara de ser posta a funcionar uma engrenagem que a partir de agora nada nem ninguém, e muito menos ele, iria alguma vez poder travar, um mecanismo de que ele próprio iria inapelavelmente ser a maior vítima. Mais tarde ou mais cedo isso teria de se dar, mas agora que, sem qualquer aviso prévio, se soubera propulsado para outra dimensão da sua vida, como se os fios que a governavam tivessem repentinamente mudado de mãos, o facto de há longo tempo o pressentir não o impediu de olhar à sua volta com estranheza, uma estranheza que antes de mais nascia de tudo à primeira vista ter ficado como estava, desafiadoramente incólume, intacto, familiar. A linha do seu destino confundir-se-ia doravante com a que, sabe-se lá onde, uma caneta ia traçando no papel página após página, mas nada na expressão dos prédios ou nos carros que indiferentemente continuavam a sulcar as ruas parecia indiciar que, dentro ou fora dele, algo se houvesse transformado ao ponto de o seu quotidiano disso se vir a ressentir. Após alguns segundos, retomou a direcção em que seguia, já não correndo mas imprimindo, ainda assim, um certo à- vontade à sua marcha, muito embora desde logo lhe fosse mais ou menos evidente que, a cada 
um dos seus passos subseqüentes à audição do grito, qualquer coisa se inscrevia dentro de si mesmo, um número, uma cifra, uma palavra susceptível de um dia se vir a converter num utensílio graças ao qual também aquele que bem no fundo de si próprio se esforçava por chegar à realidade poderia finalmente abrir caminho, rompendo através da massa do seus sangue e dos seus músculos do mesmo modo que ele através da multidão que o fim da tarde ia entretanto aglomerando nos passeios. Mas em que língua isso seria? (NAVA, 2005, p. 233- 234)

Este longo poema - em que um eu lírico assume o papel de narrador em terceira pessoa e "inventa" uma personagem sem nome, descrita apenas por pronomes masculinos - é deslocado da ideia comum que se tem de um poema: a de alguma coisa escrita em versos sem preocupações narrativas. Evidentemente, falo desta "ideia comum" sem levar em conta considerações mais profundas e, é claro, a poesia épica.

Sendo assim, "O grito" impõe diversos deslocamentos que afastam o leitor acostumado a lugares comuns. "O grito" é um incômodo híbrido de narrativa e lírica que expõe uma crise de gêneros. Acredito que isso leve a uma reflexão sobre outros deslocamentos possíveis provocados pela ação de um artista. Posso aqui citar Duchamp, que escandalizou o mundo ao dar a um urinol o estatuto de arte expondo-o num museu sob o título de $A$ fonte. Este deslocamento em particular gerou uma crise de valores na "bolsa das artes plásticas".

Cito este episódio famoso porque acredito que certos deslocamentos que penso reconhecer no poema de Luís Miguel Nava geram também uma crise de valores, ou ainda, uma intrigante inversão desses valores. Em "O grito", um "mal súbito" é provocado por uma caneta que algures desliza no papel. Toda uma atmosfera de apreensão e de terror toma o texto. Uma atmosfera comum às estratégias de suspense que servem ao entretenimento. Ocorre que, neste lugar chamado poema, tais estratégias ganham uma dinâmica e uma proporção fatais. E, por sua vez, o poema todo se constrói na direção da fatalidade. Lembremos que chamamos fatalidade àquilo que não podemos evitar.

Como este artigo construiu-se, em princípio, como uma crítica à cultura de massa e à desvalorização da arte e, principalmente, da escrita, parece que o poema de que me sirvo agora quer desmentir-me, já que falo de uma fatalidade outra: a da possível extinção da escrita ou da relação com ela, o que pode vir a ser a mesma coisa. O verso (se assim o podemos chamar em se tratando duma composição de Luís Miguel Nava) "O que ele desde sempre receara acabara de ocorrer" parece começo de uma proposta de inversão da "realidade" em que a escrita oferece entretenimento e não "perigo". Há no verbo "receara" e na locução adverbial a ideia de que um "monstro" adormecido ou ainda sonâmbulo virá à tona, não sem provocar "barulho", já que um criador impertinente põe suas mãos a serviço de "um simples gesto". Um gesto livre que só depende dele próprio para existir e para fazer existir. A escrita é esse gesto, acorda o monstro, como se pode verificar no trecho abaixo:

Corria pela rua acima quando a súbita explosão dum grito o fez parar instantaneamente. Todo o seu corpo estremeceu. $\mathrm{O}$ que ele desde sempre receara acabara de 
ocorrer: algures, nesse momento, uma caneta começara a deslizar sobre uma folha de papel, dando assim corpo àquele grito que de há muito, como as esculturas no interior da pedra, se mantinha na expectativa desse simples gesto dum escritor para atingir a realidade.

Este "atingir a realidade", que tanto me chama atenção por sua polissemia, leva-me ao início do meu texto. Afirmei há pouco, em outras palavras, que de certa forma vivemos numa sociedade em que o espanto é uma pobre encenação de mímicos. Pois, justamente, o sintagma "atingir a realidade" significa tantas coisas e, especialmente neste poema, significa o "sobrenatural". "Atingir a realidade" é chegar à realidade. É rasgar uma pedra como se tal fosse uma tripa. É também sensibilizar a realidade. E é também cair, incidir sobre a realidade como a "explosão" que figura no início do poema naviano ou, para usar as palavras de Kafka, "como um golpe no crânio ou o pior dos infortúnios" (expressões que o escritor de língua alemã usa para indicar como um "livro" nos deve "atingir").

A partir daí vem a lume um mundo extraordinário, no qual "a súbita explosão de alguma coisa" não pertence a uma cena de entretenimento vulgar ou às magras linhas duma reportagem. Não é algo esquecido nos jornais a embrulhar vasos numa loja ou peixes numa feira.

No poema "O grito", uma engrenagem, diferente das tantas engrenagens que movimentam as roldanas sociais ou tecnicistas, é posta em movimento por um ato criador e não por ato de indústria. A escrita nasce para dar contornos "maravilhosos" ao cotidiano confortável e reconhecível descrito no poema, o mesmo cotidiano que tanto nos conforta.

A interrupção duma corrida "pela rua acima" causada por uma "súbita explosão dum grito" é interrupção de ato humano, mas que pode ser lido como a interrupção do funcionamento "duma máquina”. Não à toa, "O grito" possui um cenário remissível à pintura expressionista de Edvard Munch: um quadro caro. Caro também no que diz respeito a cifras. Pode ser comprado num leilão por poucos ou acessado no supracitado Google por muitos. Sítio, aliás, onde também dormita a biografia de Luís Miguel Nava.

Já a escrita no interior d"'O grito", capaz de levar alguém para outra dimensão, é também capaz de revelar um irônico status quo presente na vida deste alguém. A partir do trecho que cito a seguir, tentarei definir o que seria este status quo:

Mais tarde ou mais cedo isso teria de se dar, mas agora que, sem qualquer aviso prévio, se soubera propulsado para outra dimensão da sua vida, como se os fios que a governavam tivessem repentinamente mudado de mãos, o facto de há longo tempo o pressentir não o impediu de olhar à sua volta com estranheza, uma estranheza que antes de mais nascia de tudo à primeira vista ter ficado como estava, desafiadoramente incólume, intacto, familiar.

A expressão "como se os fios que a governavam tivessem repentinamente mudado de mãos" indica que a personagem do poema naviano é um fantoche, e, mesmo noutra dimensão, não deixa de sê-lo. Creio que aí se estabeleça o status quo. Este homem é tragado, retirado da ficção de sua vida para "a realidade que a 
caneta constrói na folha de papel"; apesar de pensar que corria para alguma direção, já não governava sua vida. Mas o fato de recear os movimentos da nova engrenagem também aponta para outra ironia que pode sacudir nossos pensamentos sobre a vida e o mundo. Mesmo sendo um fantoche, a personagem do poema preferia seu estado anterior, preferia a dimensão por ele já conhecida. Esta sugestão parece-me mais evidente ao recortar no trecho acima o seguinte fragmento: "o facto de há longo tempo o pressentir não o impediu de olhar à sua volta com estranheza, uma estranheza que antes de mais nascia de tudo à primeira vista ter ficado como estava desafiadoramente incólume, intacto, familiar". É como se a personagem do poema se descolasse de algo que lhe parecia reconfortante, como se ele soubesse que "mãos o governavam". Por outro lado, a revolução de que ele será vítima estabelece uma fronteira que o deixa à deriva do cenário incólume a sua volta. A escrita, que em sua vida não é um elemento salvador, mas sim perturbador, mergulha no olho da personagem a "estranheza" daquele universo a sua volta, "incólume", "familiar".

Aliás, a expressão "familiar" possui uma carga semântica que neste poema torna-se ainda mais perversa. Seu cenário, até o momento em que a engrenagem começa a agir, parece impessoal como costumam ser as nossas "relações pessoais" do dia-a-dia. E, no entanto, "familiar" é verbo que deriva de "família", o primeiro "habitat" de quase toda a gente. Costuma-se, inclusive, comparar este núcleo chamado "família" a uma mulher, possivelmente a mãe, para cujo seio devemos sempre voltar. Mas à personagem do poema "O grito" resta apenas a constatação de não pertencer mais àquilo que seu olhar recebe com estranheza.

O que muito me impressiona neste poema é o modo como uma atividade intelectual, criativa e alternativa é neste texto imaginada para um mundo que não suporta a imaginação. Segundo J.G Ballard, este mundo sem imaginação assim o é porque

Vivemos num mundo governado por ficções dos mais variados tipos: massificação do consumo, publicidade, condução da política como um ramo dessa mesma publicidade, direitos de preempção exercidos pelas pantalhas televisivas sobre toda e qualquer reação original à realidade. Vivemos dentro de um enorme romance. Para o escritor é cada vez menos necessário inventar o conteúdo ficcional das suas obras. A ficção já existe, está diante dos seus olhos. A tarefa do escritor é a de inventar a realidade. (BALLARD, 1996, p. 25)

Se a atmosfera que Luís Miguel propõe parece por demais irrealista, a vida em que vivemos, descrita acima por Ballard, é bem mais, ou bem menos, que isso, já que, entre outras coisas, a escrita a deslizar no papel não move engrenagem alguma a não ser as do mercado. Assim, a escrita deixa de ser "como esculturas no interior da pedra à espera dum simples gesto" para ser o gesto desesperado de alguém desejoso de usufruir o mercado. Desta maneira, a escrita tornar-se não um grito, mas sim um baú de "não-novidades": conselhos, ligeirezas que prometem orgasmos, riqueza em semanas ou, simplesmente, asseguram que o mocinho matará o índio e resgatará a mocinha na última página.

Essa escrita, que no fundo não é "A Escrita", não traz a lume um quadro expressionista nem leva a outra dimensão. Não leva a dimensão alguma. Apenas impõe um ambiente "familiar" dos sonhos irrealizáveis que embalam nosso 
sonambulismo. A literatura de aspirações maiores que a do mercado, no entanto, nos faz perder o equilíbrio, as certezas e as esperanças de que algo virá do paraíso consumista. Ao mesmo tempo, a grande literatura parece, ela mesma, vítima duma engrenagem, como a personagem do poema naviano. Só que, diferentemente da que transporta a personagem do poema para outra dimensão, a engrenagem que vitima a literatura não nasce de um simples gesto criador, nasce da ganância da indústria cultural.

Contrariando esta imposição, Luis Miguel Nava cria uma cosmogonia conflitante com este mundo fantasmagórico que julgamos natural: este mundo de esquizofrenias socialmente aceitas; um mundo que, sem estranheza, segue sendo estranho apenas a "estranhos", a marginalizados, como escritores, leitores e poetas.

"O grito" de Luís Miguel, então, dando peso inverossímil à escrita, podenos levar ao sentido maior do que deve ser a escrita. Insisto: "um golpe no crânio". Se vivemos numa grande ficção, como afirma Ballard, devemos, em vez de recear, aspirar que uma caneta comece a deslizar no papel e nos transforme a todos na personagem do poema naviano.

Talvez, como essa personagem, comecemos a dar certo à vontade a nossa marcha e a ideia de inexorabilidade que tanto nos conforta pode desaparecer. Livres de sofismas pobres, poderemos, quem sabe, ir além do discurso, e chegar, quem sabe, àquela linguagem passível de ser recriada a partir da literatura, da poesia.

O poema "O grito", além de transformar a escrita numa força ameaçadora, atenta para o fato de ser ela linguagem, não só discurso. O discurso que é apenas discurso, ou seja, palavras que formam um acervo meramente demagógico quer seduzir, quer controlar ou apenas entreter para tornar mais fácil o caminho do convencimento.

Acredito que a questão da linguagem aparece com mais evidência em " $\mathrm{O}$ grito" no trecho final. Neste trecho que citarei mais logo, a assimilação de códigos é aliada aos movimentos duma marcha. Nada mais significativo num poema de longo fôlego em que uma correria se interrompe a partir de um gesto de escrita. A personagem retoma a direção e impõe este movimento de marcha à medida que vai sendo golpeada por elementos associáveis à linguagem, contudo sem perder seu "fervor de enigma":

Após alguns segundos, retomou a direcção em que seguia, já não correndo mas imprimindo, ainda assim, um certo à- vontade à sua marcha, muito embora desde logo lhe fosse mais ou menos evidente que, a cada um dos seus passos subseqüentes à audição do grito, qualquer coisa se inscrevia dentro de si mesmo, um número, uma cifra, uma palavra susceptível de um dia se vir a converter num utensílio graças ao qual também aquele que bem no fundo de si próprio se esforçava por chegar à realidade poderia finalmente abrir caminho, rompendo através da massa do seus sangue e dos seus músculos do mesmo modo que ele através da multidão que o fim da tarde ia entretanto aglomerando nos passeios. Mas em que língua isso seria? 
A interrogação que finaliza o poema, "Em que língua isso seria?", é reveladora duma possível guerra entre mundos, duma babel medonhamente ignorada por todos nós, que vivemos num mundo que quer cada vez mais facilmente ser decodificado. Mundo este que impõe a falsa ideia de aldeia global, na mesma medida em que se fecha financeira e culturalmente em pequenos mundos de ditaduras. O homem a romper através da massa de seu sangue diante desta falsa decodificação apresenta-se em "O grito" como o insólito capaz de sacudir as aparências.

Tentando dar fim a uma leitura que não se acaba aqui, digo que "O grito", de que me sirvo para este pequeno texto crítico, possui imagens tão aterradoras quanto inverossímeis. Paradoxalmente, essa inverossimilhança nos faz "atingir a realidade". Os cenários são hostis, o exercício da escrita e da vivência revestemse duma ignorada fantasmagoria que o poema em questão acaba por trazer à tona. E a raiz deste poema nos confronta com o que somos (sem nos darmosconta, por ingenuidade ou falsa esperteza): trocados num mercado. 


\section{REFERÊNCIAS BIBLIOGRÁFICAS}

BALLARD, J. G. Introdução do autor. In. . Crash. Lisboa: Relógio d’Água, 1996. p. 23-26.

HELDER, Herberto. Ou o poema continuo. São Paulo: A Girafa, 2006.

NAVA, Luis Miguel. Poesia Completa. Lisboa: Dom Quixote, 2002.

MAFFEI, Luis. A ética (?) e a felicidade (!) dos garotos-propaganda. In: Forum Democratico. Associazione per l'insterscambio culturale Italia Brasile Anita e Giuseppe Garibaldi Rio de Janeiro: n. 89-90, p. 39, Dezembro 2009/Janeiro 2010.

MANGUEL, Alberto. Uma história da leitura. São Paulo: Companhia das Letras, 1998. 